\title{
Reducing the kyphosis effect of anterior short thoracolumbar/lumbar scoliosis correction with an autograft fulcrum effect
}

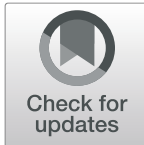

\author{
Mazda Farshad ${ }^{1}$, Andrea Frey ${ }^{1}$, Thorsten Jentzsch¹, Michael Betz', Jonas Widmer ${ }^{2,3}$ and José Miguel Spirig ${ }^{*}$
}

\begin{abstract}
Background: Anterior scoliosis correction is a powerful technique with the disadvantage of a kyphotic effect on lumbar and thoracolumbar curves. We aimed to investigate whether a cognizant interposition of a rib graft anteriorly and at the concave side of the scoliotic curve causes significant fulcrum effect to enforce scoliosis correction and to reduce interfusional kyphosis in anterior scoliosis corrections.
\end{abstract}

Methods: Twenty otherwise comparable patients with lumbar and thoracolumbar adolescent idiopathic scoliosis (AIS) curves undergoing anterior short scoliosis correction with $(n=10)$ or without $(n=10$, matched for age, gender and degree of deformity) fulcrum effect were retrospectively compared by means of radiographic measurements (sagittal and coronal profile, Cobb angles and intersegmental deformity correction angles) to evaluate the effect of this modified surgical technique.

Results: The overall amount of scoliosis correction was similar with 74 and $60 \%$ of initial curves of $57^{\circ}$ and $53^{\circ}$ in the case and control group respectively with a mean of 3 fused segments (4 screws).

Statistically relevant differences were found for intersegmental coronal cobb angles at the apex of $20^{\circ}$ to $3^{\circ}$ and $17^{\circ}$ to $9^{\circ}$ with and without fulcrum, respectively $(p<0.05)$. Creation of kyphosis in the fused segments was reduced with an interfusional kyphotic sagittal cobb angle of $15^{\circ}$ pre-operatively vs. $3^{\circ}$ post-operatively compared to the control group ( $13^{\circ}$ pre-operatively vs. $18^{\circ}$ post-operatively), $(p<0.05)$.

Conclusions: Interfusional hyperkyphosis associated with anterior scoliosis correction for thoracolumbar/lumbar curves can be reduced with cognizant positioning of the bone autograft at the antero-lateral (concave) site in the intervertebral region to create a fulcrum effect.

Trial registration: Registered at swissethics: BASEC No.: 2018-00180.

Keywords: Scoliosis, Kyphosis correction, Anterior scoliosis correction, Lumbar scoliosis, Thoracolumbar scoliosis, Kyphosis prevention

\footnotetext{
* Correspondence: jose.spirig@balgrist.ch

${ }^{1}$ Spine Division, Balgrist University Hospital, University of Zurich, Forchstrasse 340, 8008 Zurich, Switzerland

Full list of author information is available at the end of the article
}

(c) The Author(s). 2021 Open Access This article is licensed under a Creative Commons Attribution 4.0 International License, which permits use, sharing, adaptation, distribution and reproduction in any medium or format, as long as you give appropriate credit to the original author(s) and the source, provide a link to the Creative Commons licence, and indicate if changes were made. The images or other third party material in this article are included in the article's Creative Commons licence, unless indicated otherwise in a credit line to the material. If material is not included in the article's Creative Commons licence and your intended use is not permitted by statutory regulation or exceeds the permitted use, you will need to obtain permission directly from the copyright holder. To view a copy of this licence, visit http://creativecommons.org/licenses/by/4.0/ The Creative Commons Public Domain Dedication waiver (http://creativecommons.org/publicdomain/zero/1.0/) applies to the data made available in this article, unless otherwise stated in a credit line to the data. 


\section{Background}

Since the introduction of the anterior approach to scoliosis correction by Dwyer [1] and its later modification by Zielke [2], the concept has gained popularity following the introduction of rigid rod implants in the early 1990s [3-8]. The anterior approach to scoliosis correction is associated with shorter fusion distance compared to a dorsal technique, thereby sparing spinal motion segments $[9,10]$. Additionally, upper thoracic instrumentation can be avoided with the anterior approach to thoracolumbar curves preventing the need to treat compensatory thoracic curves [11]. The disadvantage of this method is a possible reduction of lordosis or a kyphogenic effect caused by a full discectomy and the subsequently applied compression force for bone on bone fusion. Previous studies have demonstrated radiographic and satisfying clinical outcomes of anterior spine fusions over a short-term follow-up ( $2-5$ years) as well as a longer follow-up (12-23 years) [12-14]. However, one main drawback of anterior scoliosis correction remains the occurrence of hyperkyphosis in up to $40 \%$ of patients [15].

To our knowledge there are no reports regarding short anterior fusion using cognizant interposition of a rib autograft at the anterior and concave side of the scoliotic curve thereby creating a fulcrum effect to address the problem of kyphosis creation and enhancing coronal scoliosis correction. Therefore, in this study we report the immediate radiographic results, describe the method of choosing fusion levels as well as the specific technique of this surgical procedure.

\section{Patients and method}

The present study was approved by the local ethics committee (Swissethics, BASEC No.: 2018-00180) on research involving humans. Every patient involved in this study gave written informed consent before inclusion.

In this cohort study a retrospective review of a very selective patient population with the diagnosis of adolescent idiopathic scoliosis (AIS) with the major curve deformity located in the thoracolumbar or lumbar spine region was performed. All these patients underwent selective short anterior correction fusion with $(n=10$, cases) or without ( $n=10$, controls) interbody interposition of bone autograft specifically at the anterior and concave side of the scoliotic curve. The controls were selected from 118 AIS patients to match the cases according to age, Risser stage, sex, type and degree of scoliotic deformity (Table 1).

Radiological measurements were performed by an independent observer on EOS radiographs (antero-posterior and lateral radiographs) immediately prior to surgery and 6 weeks postoperatively to determine the direct effect of corrective deformity changes according to the recommendation of the SRS [16]. Cobb angle vertebral
Table 1 Patient demographic data $(n=20)$

\begin{tabular}{|c|c|c|c|}
\hline \multirow[t]{2}{*}{ Variable } & \multicolumn{2}{|c|}{ Measurements (median [IQR]) } & \multirow{2}{*}{$\begin{array}{l}P \text { - } \\
\text { value }\end{array}$} \\
\hline & Cases $(n=10)$ & Controls $(n=10)$ & \\
\hline Age (y) & $15(3)$ & $16(3)$ & 0.732 \\
\hline \multicolumn{4}{|l|}{$\operatorname{Sex}(n)$} \\
\hline Female & 9 & 9 & 1.000 \\
\hline Males & 1 & 1 & \\
\hline Segments (n) & $4(0)$ & $4(1)$ & 0.185 \\
\hline \multicolumn{4}{|l|}{ Lenke (n) } \\
\hline 5 & 4 & 5 & 0.653 \\
\hline 6 & 6 & 5 & \\
\hline \multicolumn{4}{|l|}{ Risser (n) } \\
\hline 0 & 0 & 2 & 0.361 \\
\hline 1 & 2 & 1 & \\
\hline 2 & 3 & 1 & \\
\hline 3 & 1 & 1 & \\
\hline 4 & 4 & 3 & \\
\hline 5 & 0 & 2 & \\
\hline
\end{tabular}

Abbreviations: IQR (interquartile range), $y$ (years)

*Wilcoxon rank sum test or Chi-square test

levels were determined on the preoperative radiographs with the same levels measured on subsequent radiographs to remain consistent for statistical comparison [17]. In addition, intervertebral Cobb angle and the Cobb angle at the apex of fused levels was measured prior to surgery and postoperatively in coronal and sagittal plane. Coronal balance was measured by lateral displacement of a $\mathrm{C} 7$ coronal plumbline from the central sacral vertical line (CSVL) [18].

Sagittal alignment measures included the T1 to T12 thoracic kyphosis and lumbar lordosis (L1 to S1). For regional alignment, apical vertebral translation (AVT) was measured as the distance from the geometrical center of the apical vertebra [19] to the central sacral vertical line. Apical vertebral rotation (AVR) or lowest instrumented vertebra (LIV) rotation was graded according to the Nash-Moe method [20].

\section{Statistics}

Due to mainly non-normal distribution, medians (interquartile ranges [IQR]) are provided. Comparison of measurements was done with the Wilcoxon rank sum test (for continuous data) and Chi-squared test (for categorical data) for unpaired groups and the Wilcoxon signed rank test for paired groups. Stata/IC (version 13.1; StataCorp LP, College Station, TX, USA) was used.

For this study no funding source was required.

\section{Surgical technique}

The main surgical technique is described elsewhere in detail [21]. Here we summarize the main steps and the new modification for creation of the fulcrum effect. 
To determine fusion length preoperative anteroposterior, lateral as well as supine-side bending radiographic imaging of the whole spine were obtained for all patients. The most caudal opening disc on the concavity of the lumbar curve was not included into the fusion. The number of vertebrae beginning from the apex of scoliosis to the LIV was determined in antero-posterior imaging, whereby the apex can either be a disc or a vertebra. After determining the number of vertebrae, the same number was added proximal to the apex to determine the proximal arm of instrumentation. The average length of fusion was 4 vertebrae (min. 3- max. 5). The distal end of fusion was L2 in five and L3 in another five patients.

All surgical procedures of the case group were conducted by a single surgeon (blinded for review purposes) utilizing the same operative technique. Surgery was performed under continued spinal cord monitoring via SEP and MEP. Following double lung intubation all patients were placed in a lateral decubitus position. In all cases a thoraco-phrenico-lumbotomy, including partial resection of a rib, was conducted to expose the thoracolumbar and lumbar intervertebral discs. Subsequently, a 360degree removal was accomplished through complete anulotomy and discectomy including the removal of the anterior and the posterior longitudinal ligament. The exposed vertebrae were instrumented using a single titanium screw with bicortical purchase.

The primarily excised rib was used as structural graft within the intervertebral disc space. Importantly, decortication of the endplates prior to autograft insertion was performed. This increases vascularity and thereby permits speedier osseous healing. The rib autograft $(1 \times 1 \times 0$, $3 \mathrm{~cm}$ ) was placed between the endplates in the concave curve side to facilitate scoliosis correction and anteriorly to reduce the kyphosis effect created by total discectomy and compression for bone on bone fusion (Fig. 1 and Fig. 2).

A titanium rod was implanted. The rod was fixed to the most proximal screw and subsequently reduced into the distal screws. Subsequently compression forceps were used to achieve final correction aided by the intervertebral rib autograft.

Average surgery time was 237 min with a mean blood loss of $370 \mathrm{ml}$. Postoperatively all patients were placed in intermediate care for $48 \mathrm{~h}$ observation. Ambulation and respiratory therapy were introduced under guidance of physiotherapists on the following day. The thorax drain was removed within $48-72 \mathrm{~h}$ following surgery. On average patients were dismissed from hospital within 8 days. The first outpatient appointment was performed within 6 weeks of surgery. Six weeks postoperatively, patients were permitted to resume light sportive activities, including cycling and swimming.

No neurological complications, pseudarthrosis or implant-related complications were noted in both groups.

\section{Results}

\section{Main curve correction}

The median pre-operative Cobb angle of the main curve was $57^{\circ}$ in the case (IQR 13) and $53^{\circ}$ in the control (IQR 12) group. With a mean of 4 fused segments, the scoliotic curves improved by $74 \%$ to $12^{\circ}$ (IQR 17 ) immediately post-operatively and remained mostly unchanged with $15^{\circ}$ (IQR 16) at 6 weeks in the case group. In the control group fusion was performed over 3.6 segments with a postsurgical median of $20^{\circ}$ (IQR 11 ) and $21^{\circ}$ (IQR 10) at 6 weeks post-operatively. This corresponds to a $60 \%$ improvement of the scoliosis.
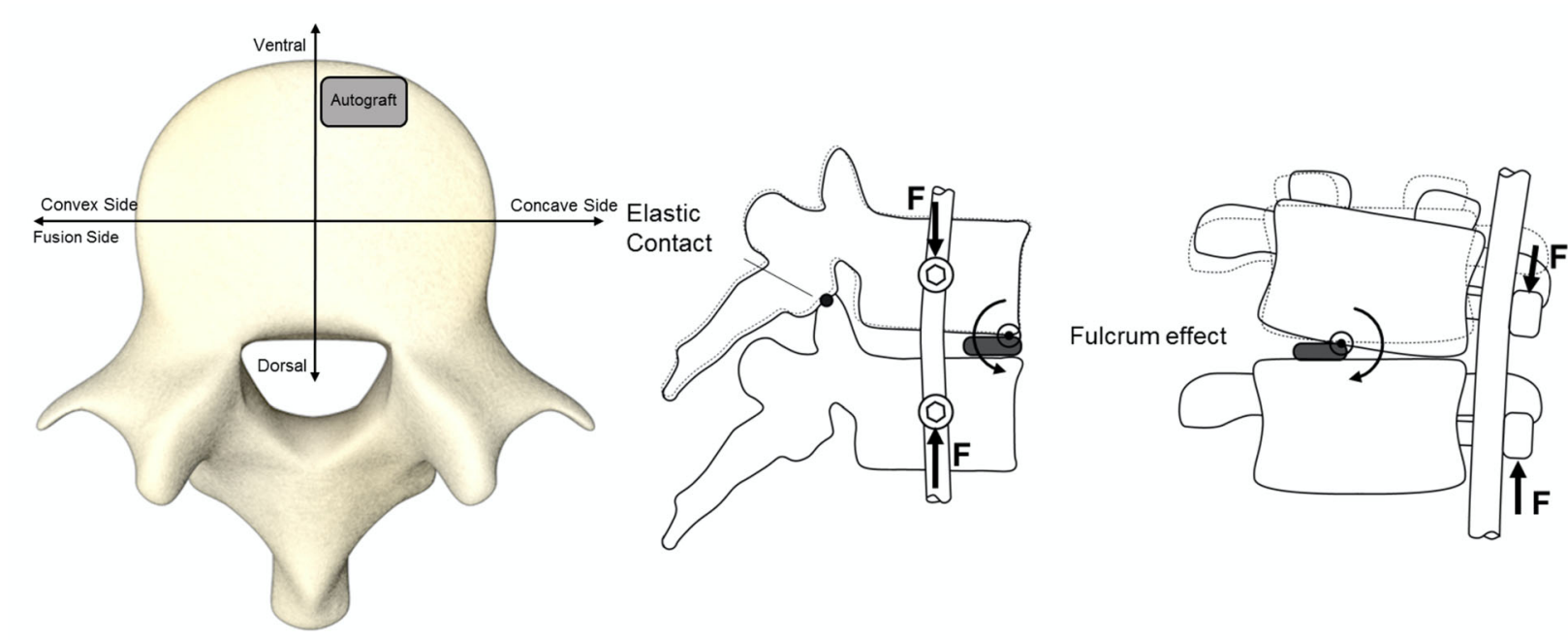

Fig. 1 Correct placement of rib autograft (anterolateral at concave side of curve) with segmental fulcrum effect 


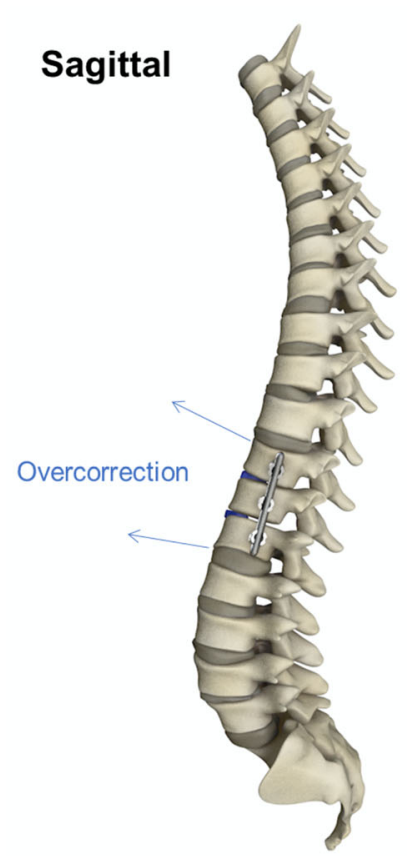

With Fulcrum
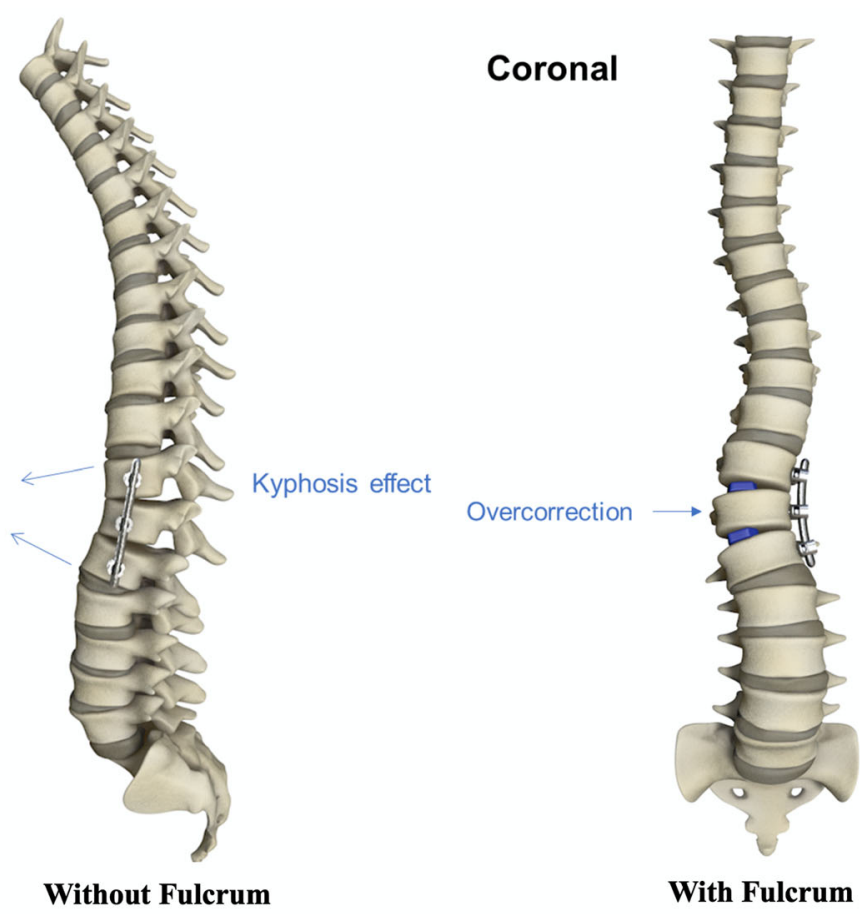

With Fulcrum

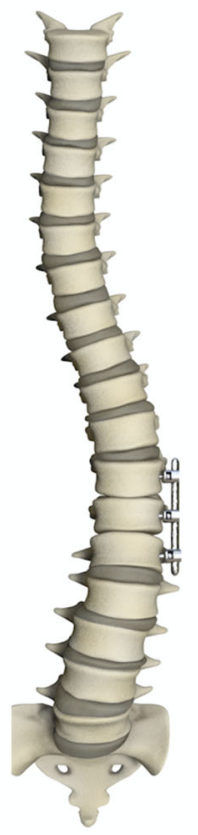

Without Fulcrum

Fig. 2 Overcorrection achieved with fulcrum effect in both sagittal and coronal plane. Kyphosis effect seen in sagittal plane without fulcrum

\section{Apical intervertebral Cobb angle correction}

There was a significant difference observed in the intervertebral Cobb angle at the apex of the scoliosis between the case and control group. With a pre-operative median of $20^{\circ}$ (IQR 4 ) the angle improved by $88 \%$ to $3^{\circ}$ (IQR 2) immediately after surgery. In contrast, the intervertebral Cobb angle in the control group measured $17^{\circ}$ (IQR 6) at time of surgery, improving with $53 \%$ to $9^{\circ}$ (IQR 2) after surgery.

\section{Apical vertebral translation and coronal balance}

Apical vertebral translation and coronal balance were not significantly different between the two groups at each time point.

\section{Thoracic kyphosis}

Thoracic kyphosis changed from a median of $37^{\circ}$ (IQR 16) to $36^{\circ}$ (IQR 11) 6 weeks postoperatively in the case and from a median of $37^{\circ}$ (IQR 11 ) prior to surgery, increasing to $45^{\circ}$ (IQR 15) post-operatively in the control group, respectively.

\section{Lumbar lordosis}

The pre-operative median lumbar lordosis did not decrease significantly from $53^{\circ}$ (IQR 20) to $52^{\circ}$ (IQR 12) at 6 weeks postoperatively in the case group versus $57^{\circ}$ (IQR 7) to $64^{\circ}$ (IQR 12) in the control group.

\section{Apical vertebral rotation}

The apical vertebral rotation was neither significant in the case nor in the control group (IQR 1) (Table 2).

\section{Coronal Cobb angle at the level of instrumentation}

The coronal Cobb angle at the level of instrumentation improved from a median of $45^{\circ}$ (IQR 19) to $5^{\circ}$ (IQR 12) 6 weeks postoperatively in the case group compared to $36^{\circ}$ (IQR 9) to $14^{\circ}$ (IQR 10) in the control group.

\section{Sagittal Cobb angle at the level of instrumentation}

In the sagittal profile the case group showed a statistically relevant reduction of kyphotic angle within the instrumented levels with a median of $14^{\circ}$ (IQR 6) preoperatively to $3^{\circ}$ (IQR 8 ) 6 weeks postoperatively whereas in the control group an increasement of kyphosis was observed from $13^{\circ}$ to $18^{\circ}$.

\section{Thoracic kyphosis above instrumentation}

The thoracic kyphosis above instrumentation changed non significantly from a median of $14^{\circ}$ (IQR 5) to $12^{\circ}$ (IQR 6) 6 weeks postoperatively in the case group and from $22^{\circ}$ (IQR 8) to $19^{\circ}$ (IQR 19) post-operatively in the control group.

\section{Lumbar lordosis below instrumentation}

The pre-operative median lumbar lordosis below the level of instrumentation decreased from $47^{\circ}$ (IQR 23) to 
Table 2 Comparison of standard radiological measurements between cases and controls $(n=20)$

\begin{tabular}{|c|c|c|c|}
\hline \multirow[t]{2}{*}{ Variable } & \multicolumn{3}{|c|}{ Measurements (median [IQR]) } \\
\hline & Cases $(n=10)$ & Controls $(n=10)$ & $P$-value ${ }^{*}$ \\
\hline \multicolumn{4}{|l|}{ Overall Cobb angle $\left(^{\circ}\right)$} \\
\hline Pre-op & $57(13)$ & $53(12)$ & 0.732 \\
\hline Post-op & $11(17)$ & $20(11)$ & 0.403 \\
\hline 6 wks & $15(16)$ & $21(10)$ & 0.427 \\
\hline$\Delta$ (pre-op vs 6 wks) & $-40(11)$ & $-36(12)$ & 0.448 \\
\hline \multicolumn{4}{|l|}{$\mathrm{AVT}(\mathrm{mm})$} \\
\hline Pre-op & $45(15)$ & $41(19)$ & 0.140 \\
\hline Post-op & $11(7)$ & $15(11)$ & 0.383 \\
\hline 6 wks & $14(12)$ & $18(4)$ & 0.307 \\
\hline$\Delta$ (pre-op vs 6 wks) & $-32(15)$ & $-21(16)$ & $0.028^{\dagger}$ \\
\hline \multicolumn{4}{|l|}{ Coronal balance $(\mathrm{mm})$} \\
\hline Pre-op & $24(4)$ & $22(10)$ & 0.197 \\
\hline 6 wks & $23(4)$ & $19(7)$ & 0.139 \\
\hline$\Delta$ (pre-op vs 6 wks) & $-1.5(6)$ & $-2.5(10)$ & 1.000 \\
\hline \multicolumn{4}{|c|}{ Apical intervertebral Cobb angle $\left(^{\circ}\right)$} \\
\hline Pre-op & $20(6)$ & $17(6)$ & 0.363 \\
\hline Post-op & $3(2)$ & $9(2)$ & $<0.001^{\dagger}$ \\
\hline 6 wks & $2(1)$ & $9(2)$ & $<0.001^{\dagger}$ \\
\hline$\Delta$ (pre-op vs 6 wks) & $-18(8)$ & $-10(8)$ & $0.002^{\dagger}$ \\
\hline \multicolumn{4}{|l|}{ Thoracic kyphosis $\left({ }^{\circ}\right)$} \\
\hline Pre-op & $37(16)$ & $37(11)$ & 0.910 \\
\hline 6 wks & $36(11)$ & $45(15)$ & 0.064 \\
\hline$\Delta$ (pre-op vs 6 wks) & $-1(6)$ & $9(7)$ & $0.010^{\dagger}$ \\
\hline \multicolumn{4}{|l|}{ Lumbar lordosis $\left({ }^{\circ}\right)$} \\
\hline Pre-op & $53(20)$ & $57(7)$ & 0.544 \\
\hline 6 wks & $52(12)$ & $64(12)$ & $0.023^{\dagger}$ \\
\hline$\Delta$ (pre-op vs 6 wks) & $-4(7)$ & $3(6)$ & $0.017^{\dagger}$ \\
\hline \multicolumn{4}{|c|}{ Apical vertebral rotation (Nash and Moe Grade) } \\
\hline Pre-op & $2(1)$ & $2(1)$ & 1.00 \\
\hline 6 wks & $2(1)$ & $2(1)$ & 0.374 \\
\hline$\Delta$ (pre-op vs 6 wks) & $-1(1)$ & $-1(1)$ & 0.593 \\
\hline
\end{tabular}

Abbreviations: IQR (interquartile range), $n$ (number), ${ }^{\circ}$ (degrees), AVT (apical vertebral translation) $\mathrm{mm}$ (millimeters), op (operatively), wks (weeks), vs (versus), $\Delta$ (delta [difference])

"Wilcoxon rank sum test or Chi-square test

${ }^{\dagger}$ Statistically significant difference

$39^{\circ}$ (IQR 19) at 6 weeks postoperatively in the case group whereas a substantial subfusional, compensatory increasement in lordosis from $42^{\circ}$ (IQR 14) to $45^{\circ}$ (IQR 12) was measured in the control group (Table 3 ).

\section{Discussion}

The main disadvantage of a short anterior lumbar scoliosis correction is its potential kyphogenic effect. We investigated whether interbody cognizant interposition of
Table 3 Comparison of interfusional and sub- and epifusional radiological measurements between cases and controls $(n=20)$

\begin{tabular}{|c|c|c|c|}
\hline \multirow[t]{2}{*}{ Variable } & \multicolumn{3}{|c|}{ Measurements (median [IQR]) } \\
\hline & Cases $(n=10)$ & Controls $(n=10)$ & $P$-value \\
\hline \multicolumn{4}{|c|}{ Coronal Cobb angle at instrumented level $\left(^{\circ}\right)$} \\
\hline Pre-op & $45(19)$ & $36(9)$ & 0.129 \\
\hline Post-op 6 wks & $5(12)$ & $14(10)$ & 0.058 \\
\hline$\Delta$ (pre-op vs 6 wks) & $-41(5)$ & $-24(15)$ & $0.002^{\dagger}$ \\
\hline \multicolumn{4}{|c|}{ Sagittal Cobb angle at instrumented level $\left(^{\circ}\right)$} \\
\hline Pre-op & $14(6)$ & $13(11)$ & 0.363 \\
\hline Post-op 6 wks & $3(8)$ & $18(18)$ & $0.006^{\dagger}$ \\
\hline$\Delta$ (pre-op vs 6 wks) & $-12(11)$ & $5(4)$ & $0.001^{\dagger}$ \\
\hline \multicolumn{4}{|c|}{ Epifusional sagittal Cobb angle at non-instrumented level $\left(^{\circ}\right)$} \\
\hline Pre-op & $14(5)$ & $22(8)$ & $0.023^{\dagger}$ \\
\hline Post-op 6 wks & $12(6)$ & $19(19)$ & 0.211 \\
\hline$\Delta$ (pre-op vs 6 wks) & $-2(2)$ & $-6(6)$ & 0.087 \\
\hline
\end{tabular}

Subfusional sagittal Cobb angle at non-instrumented level $\left({ }^{\circ}\right)$

$\begin{array}{llll}\text { Pre-op } & 47(23) & 42(14) & 0.762 \\ \text { Post-op 6 wks } & 39(19) & 45(12) & 0.112 \\ \Delta \text { (pre-op vs 6 wks) } & -4(7) & 6(5) & 0.006^{\dagger}\end{array}$

Abbreviations: IQR (interquartile range), $n$ (number), ${ }^{\circ}$ (degrees), op

(operatively), wks (weeks), vs (versus), $\Delta$ (delta [difference])

*Wilcoxon rank sum test or Chi-square test

${ }^{\dagger}$ Statistically significant difference

bone autograft at the anterior and concave side of the scoliotic lumbar and thoracolumbar curve would reduce the undesired kyphogenic effect. We found that the described technique seems powerful in this regard, despite technically simple.

An anterior approach to scoliosis correction was first described by Dwyer in 1969 [1, 22]. His technique included resection of the discs and applying compressive forces with a cable and screw system. The major drawback of this technique was a limited stability since the flexible cable still allowed some amount of motion. Therefore, implant failure and subsequent pseudoarthrosis were frequent complications with this technique [2325].

In 1976 the surgical technique was modified by Zielke substituting the wires with threaded rods (a Harrington compression rod) to connect the implanted screws [2]. This provided more stability against rotational forces and allowed to apply some derotational maneuver during surgery. Later on, Hall and Bernstein introduced a surgical method of shorter fusion using Zielke implants in adolescents with flexible idiopathic thoracolumbar scoliosis [3, 5]. They emphasized the importance of overcorrection in short anterior correction to achieve acceptable results. Since the early 1990s, following the introduction of rigid screw-rod implants, there have been numerous reports on the anterior correction of 
thoracolumbar/ lumbar scoliosis [4-8]. However, one main drawback of anterior scoliosis correction remains the occurrence of hyperkyphosis in up to $40 \%$ of patients by applying anterior compression forces [15]. Whilst other studies have described the use of cages for anterior correction of thoracolumbar/lumbar curves to maintain lordosis $[10,26]$ there is no study evaluating the strategic important positioning of a structural interbody bone autograft at the anterior and concave side of the scoliotic curve to introduce a fulcrum and counteract the kyphogenic effect of anterior scoliosis correction. (Fig. 3a and Fig. 3b).

However, the use of rib autograft has been described earlier $[4,5,9]$ and is a known factor in contributing to rapid fusion.

We could clearly show that while those patients, in whom the autograft fulcrum effect was used, demonstrated a correction of preoperative thoracolumbar/lumbar kyphosis at the instrumented levels $\left(14^{\circ}\right.$ to $\left.3^{\circ}\right)$, the control group showed a clear increase in kyphosis $\left(13^{\circ}\right.$ to $\left.18^{\circ}\right)$. Kelly et al. [4] who used rib autograft without specifically describing the positioning of the autograft showed a significant increase in kyphosis from $2^{\circ}$ to $11^{\circ}$ in the instrumented levels. However, similar to our study, they instrumented 3 to 4 segments and they had no significant change in global thoracic kyphosis and lumbar lordosis from pre- to postoperative. Measurements for lumbar lordosis and thoracic kyphosis were performed at different levels than in our study wherefore comparison of absolute numbers are not reasonable. Bernstein et al. [5] who used rib autograft without specific positioning for fusion of 2 to 3 segments reported similarly a significant increase in kyphosis from $4^{\circ}$ to $10^{\circ}$ within instrumented levels. Measurements of global thoracic kyphosis and lumbar lordosis were not reported. Min et al. [9] fused on average 3 segments using also an unspecific rib autograft technique and reported no significant change in global thoracic kyphosis and lumbar lordosis. Unfortunately, no measurements of cobb angle in the instrumented segments were performed. Overall, it is reasonable that the amount of creation or reduction of kyphosis is somehow depending on
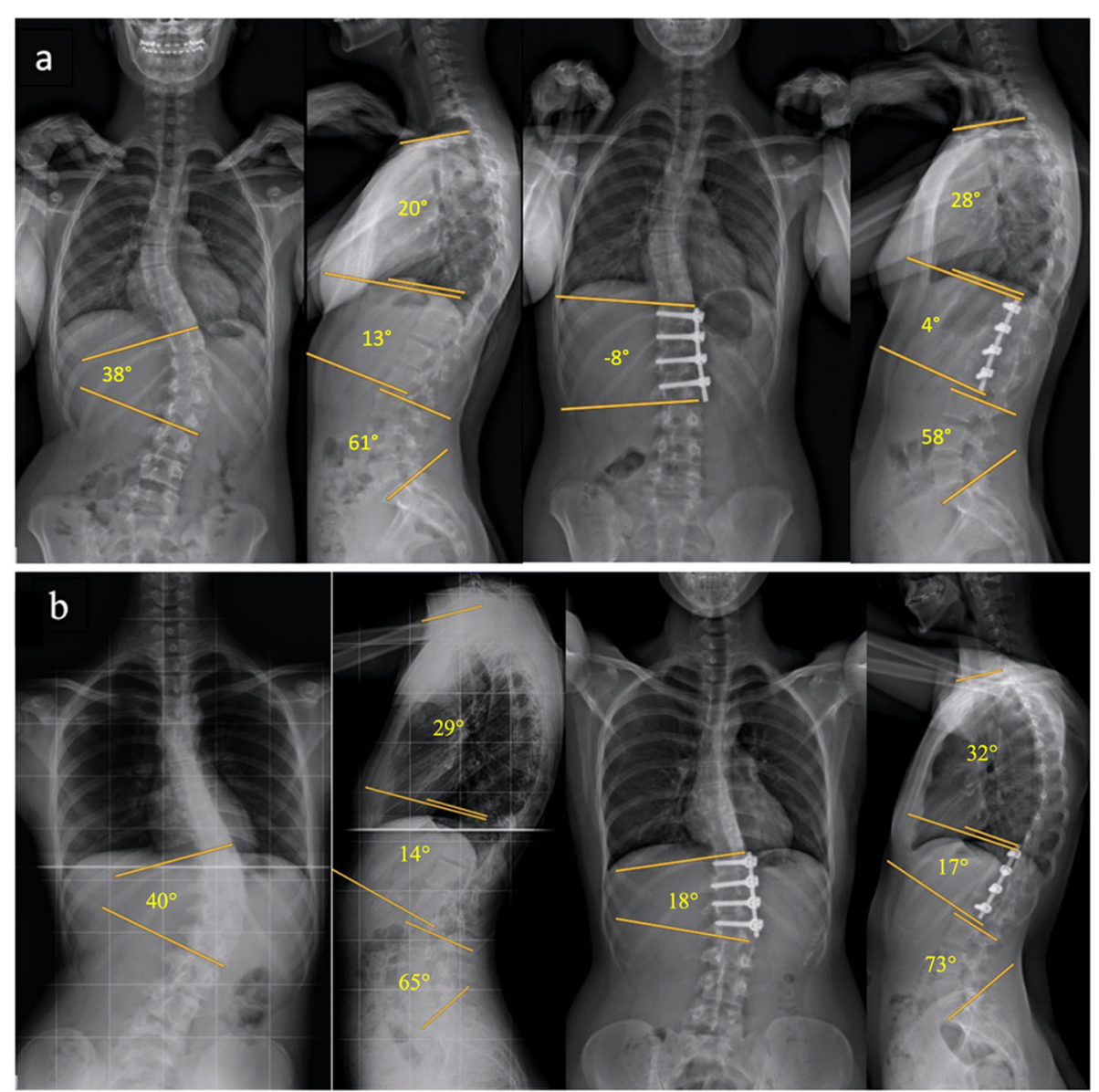

Fig. 3 a Standing PA and lateral radiographs with pre- and postoperative Cobb angles in a patient operated with autograft fulcrum effect. $\mathbf{b}$ Standing PA and lateral radiographs with pre- and postoperative Cobb angles in a control patient operated without autograft fulcrum effect 
the exact positioning of the rib autograft; While a dorsal positioning plausibly does not reduce kyphosis, an anterior intervertebral position seems to reduce the kyphosing effect of anterior scoliosis correction. This was also observed in our case group using the rib autograft fulcrum effect.

In addition, the lateral concave side positioning allows an even stronger coronal correction than the bone-onbone fusion technique allowing shorter fusion segments for over-correction of the apex, potentially. However, this correction difference $(74 \%$ versus $60 \%$ ) was not significant in our study. The correction of the case group in our study was comparable with results of other studies using an unspecific rib autograft technique $(87 \%$ by Bernstein et al. [5], $64 \%$ by Kelly et al. [4], 67\% by Min et al. [9]).

The results of this study, however, need to be interpreted with regard to their limitations.

First, this was a retrospective analysis of a limited number of patients. However, in anticipation of this limitation and in order to increase the validity of the study, case-control matching was carried out. Due to homogeneity of the comparative groups the strength of the study was thereby increased.

Second, a 6 week follow-up is not enough for a surgical outcome study. However, we specifically report the immediate results of a modified surgical technique and do not claim to report any associated clinical outcome measures or long term follow up. We believe that the promising early results of this surgical technique which eliminates a major limitation (creation of kyphosis) of an otherwise advantageous surgical procedure for correction of scoliosis (anterior short correction) might be of interest to the spine surgery community. The modification described here is based on the established technique of bone-autograft interposition, but with a cognizant strategic positioning.

Third, the radiological assessment of the scoliosis and its correction was made on ap and lateral radiographs and not 3D-enabled imaging. While we believe, that the fulcrum effect might be even more valuable if the evaluations were made in a 3D-modality imaging, this hypothesis remains untested.

\section{Conclusion}

Based on this study we conclude that anterior short fusion using antero-, concave-lateral positioning of a rib autograft as a fulcrum is a valuable technical addition for correction of thoracolumbar/lumbar idiopathic scoliosis. In addition to reduction of the otherwise occurring kyphosis effect with anterior scoliosis correction, a better short (over-) correction of the apex seems possible. Whilst the initial results show promising results, follow-up studies will be necessary to validate long term results and demonstrate preservation of the achieved correction.

\section{Acknowledgements}

Not applicable.

\section{Authors' contributions}

MF, JS, TJ made major contributions in conception and design and/or analysis and interpretation of patient data. AF was a major contributor in data acquisition. JS, MF, TJ, AF, MB and JW were contributors in drafting the manuscript or revising it critically for important intellectual content. All authors read and approved the final manuscript.

\section{Funding}

No financial funding sources were acquired for this study.

\section{Availability of data and materials}

The datasets used and/or analyzed during the current study are available from the corresponding author on reasonable request.

\section{Ethics approval and consent to participate}

The study has been performed in accordance with the Declaration of Helsinki and ethical approval was obtained from the local ethics committee (Swissethics, BASEC No.: 2018-00180). Written informed consent was obtained from legally authorized representatives before the study.

\section{Consent for publication}

Not applicable.

\section{Competing interests}

The authors declare that they have no conflict of interest.

\section{Author details}

${ }^{1}$ Spine Division, Balgrist University Hospital, University of Zurich, Forchstrasse 340, 8008 Zurich, Switzerland. 'Laboratory for Orthopaedic Biomechanics, Balgrist University Hospital, Zürich, Switzerland. ${ }^{3}$ Institute of Biomechanics, ETH Zurich, Zurich, Switzerland.

Received: 18 October 2020 Accepted: 9 February 2021

Published online: 23 February 2021

\section{References}

1. Dwyer AF, Newton NC, Sherwood AA. An anterior approach to scoliosis. A preliminary report. Clin Orthop Relat Res. 1969;62:192-202.

2. Zielke K, Stunkat R, Beaujean F. Ventrale derotations-spondylodesis (author's transl). Archiv fur orthopadische und Unfall-Chirurgie. 1976;85(3):257-77.

3. Hall JE. Short segment anterior instrumentation for thoracolumbar scoliosis. In: The textbook of spinal surgery; 1997.

4. Kelly DM, McCarthy RE, McCullough FL, Kelly HR. Long-term outcomes of anterior spinal fusion with instrumentation for thoracolumbar and lumbar curves in adolescent idiopathic scoliosis. Spine. 2010;35(2):194-8.

5. Bernstein RM, Hall JE. Solid rod short segment anterior fusion in thoracolumbar scoliosis. J Pediatr Orthop B. 1998;7(2):124-31.

6. Haher TR, Merola A, Zipnick RI, Gorup J, Mannor D, Orchowski J. Metaanalysis of surgical outcome in adolescent idiopathic scoliosis. A 35-year English literature review of 11,000 patients. Spine. 1995;20(14):1575-84.

7. Ogilvie JW. Anterior spine fusion with Zielke instrumentation for idiopathic scoliosis in adolescents. Orthop Clin North Am. 1988;19(2):313-7.

8. Moe JH, Purcell GA, Bradford DS. Zielke instrumentation (VDS) for the correction of spinal curvature. Analysis of results in 66 patients. Clin Orthop Relat Res. 1983;180:133-53.

9. Min K, Hahn F, Ziebarth K. Short anterior correction of the thoracolumbar/ lumbar curve in king 1 idiopathic scoliosis: the behaviour of the instrumented and non-instrumented curves and the trunk balance. Eur Spine J. 2007;16(1):65-72.

10. Lowe TG, Betz R, Lenke L, Clements D, Harms J, Newton P, et al. Anterior single-rod instrumentation of the thoracic and lumbar spine: saving levels. Spine. 2003;28(20):208-16.

11. Sanders AE, Baumann R, Brown H, Johnston CE 2nd, Lenke LG, Sink E. Selective anterior fusion of thoracolumbar/lumbar curves in adolescents: when can the associated thoracic curve be left unfused? Spine. 2003;28(7): 706-13

12. Otani K, Saito M, Sibasaki K. Anterior instrumentation in idiopathic scoliosis: a minimum follow-up of 10 years. Int Orthop. 1997;21(1):4-8. 
13. Sweet FA, Lenke LG, Bridwell KH, Blanke KM, Whorton J. Prospective radiographic and clinical outcomes and complications of single solid rod instrumented anterior spinal fusion in adolescent idiopathic scoliosis. Spine. 2001;26(18):1956-65.

14. Sudo H, Ito M, Kaneda K, Shono Y, Abumi K. Long-term outcomes of anterior dual-rod instrumentation for thoracolumbar and lumbar curves in adolescent idiopathic scoliosis: a twelve to twenty-three-year follow-up study. J Bone Joint Surg Am. 2013;95(8):e49.

15. Betz RR, Harms J, Clements DH 3rd, Lenke LG, Lowe TG, Shufflebarger HL, et al. Comparison of anterior and posterior instrumentation for correction of adolescent thoracic idiopathic scoliosis. Spine. 1999;24(3):225-39.

16. Merola AA, Haher TR, Brkaric M, Panagopoulos G, Mathur S, Kohani O, et al. A multicenter study of the outcomes of the surgical treatment of adolescent idiopathic scoliosis using the Scoliosis Research Society (SRS) outcome instrument. Spine. 2002;27(18):2046-51.

17. Cobb JR. Outline for study of scoliosis. In: Outline for the Study of Scoliosis; 1948. p. 261-75.

18. Jackson RP, McManus AC. Radiographic analysis of sagittal plane alignment and balance in standing volunteers and patients with low back pain matched for age, sex, and size. A prospective controlled clinical study. Spine. 1994;19(14):1611-8.

19. Sudo H, Kaneda K, Shono Y, Iwasaki N. Selection of the upper vertebra to be instrumented in the treatment of thoracolumbar and lumbar adolescent idiopathic scoliosis by anterior correction and fusion surgery using dual-rod instrumentation: a minimum 12-year follow-up study. Spine J. 2016;16(3): 281-7.

20. Nash CL Jr, Moe JH. A study of vertebral rotation. J Bone Joint Surg Am. 1969:51(2):223-9.

21. Min K, Haefeli M, Mueller D, Klammer G, Hahn F. Anterior short correction in thoracic adolescent idiopathic scoliosis with mini-open thoracotomy approach: prospective clinical, radiological and pulmonary function results. Eur Spine J. 2012;21(Suppl 6):765-72.

22. Dwyer AF, Schafer MF. Anterior approach to scoliosis. Results of treatment in fifty-one cases. J Bone Joint Surg Br. 1974;56(2):218-24.

23. Hsu LC, Zucherman J, Tang SC, Leong JC. Dwyer instrumentation in the treatment of adolescent idiopathic scoliosis. J Bone Joint Surg Br. 1982;64(5): 536-41.

24. Kohler R, Galland O, Mechin H, Michel CR, Onimus M. The Dwyer procedure in the treatment of idiopathic scoliosis. A 10-year follow-up review of 21 patients. Spine. 1990;15(2):75-80.

25. Luk KD, Leong JC, Reyes L, Hsu LC. The comparative results of treatment in idiopathic thoracolumbar and lumbar scoliosis using the Harrington, Dwyer, and Zielke instrumentations. Spine. 1989;14(3):275-80.

26. Sweet FA, Lenke LG, Bridwell KH, Blanke KM. Maintaining lumbar lordosis with anterior single solid-rod instrumentation in thoracolumbar and lumbar adolescent idiopathic scoliosis. Spine. 1999;24(16):1655-62.

\section{Publisher's Note}

Springer Nature remains neutral with regard to jurisdictional claims in published maps and institutional affiliations.

Ready to submit your research? Choose BMC and benefit from:

- fast, convenient online submission

- thorough peer review by experienced researchers in your field

- rapid publication on acceptance

- support for research data, including large and complex data types

- gold Open Access which fosters wider collaboration and increased citations

- maximum visibility for your research: over $100 \mathrm{M}$ website views per year

At $\mathrm{BMC}$, research is always in progress.

Learn more biomedcentral.com/submissions 